Supporting Information

\title{
Boosted Oxygen Evolution Reaction by Controllable Fluoridation on Porous Cobalt-Iron Nanoflakes
}

\author{
$\mathrm{Xu}$ Han,${ }^{\dagger}$ Longjie Lin, ${ }^{\dagger}$ Chengang Pei, and $\mathrm{Xu} \mathrm{Yu}{ }^{*}$
}

School of Chemistry and Chemical Engineering, Yangzhou University, Yangzhou,

225000, China

*Corresponding Author. E-mail: yxypz15@yzu.edu.cn (X. Yu)

${ }^{\dagger}$ These authors contributed equally to this work. 


\section{Characterizations}

Powder X-ray diffraction (XRD) patterns were recorded on a Bruker D8 Advance powder. X-ray diffractometer using a $\mathrm{Cu} \mathrm{K \alpha}(\lambda=1.5405 \AA)$ radiation source operating at $40 \mathrm{kV}$ and $30 \mathrm{~mA}$ at a scanning rate of $5^{\circ} \mathrm{min}^{-1}$. The morphology and microstructure of the product were analyzed by scanning electron microscopy (FESEM, Hitachi, S-4800 II, Japan) and transmission electron microscopy (TEM, Philips, TECNAI 12, Holland). Highresolution transmission electron microscopy (HRTEM) was performed on a FEI Tecnai G2 F30 STWIN (USA) operating at $300 \mathrm{kV}$. Surface analysis of the sample was studied by Xray photoelectron spectroscopy (XPS, Thermo Science, ESCALAB 250Xi, USA).

\section{Electrochemical measurements}

The electrochemical measurements were performed on a CHI660E electrochemical workstation ( $\mathrm{CH}$ Instruments, shanghai) at room temperature $\left(25{ }^{\circ} \mathrm{C}\right)$. The OER performance was measured in a standard three-electrode cell using the glassy carbon electrode (GC, $3 \mathrm{~mm}$ diameter, $0.07 \mathrm{~cm}^{-2}$ ) as support working electrode while the graphite rod and the saturated calomel electrode (SCE) were used as the counter and reference electrode, respectively. The prepared working electrode was placed in $1 \mathrm{M} \mathrm{KOH}$ treated with $\mathrm{N}_{2}$ for electrochemical testing. The catalyst ink and working electrode were prepared as follows. $5 \mathrm{mg}$ of catalysts, $950 \mu \mathrm{L}$ of ethanol, and $50 \mu \mathrm{L}$ of Nafion solution were mixed and ultrasonicated for $30 \mathrm{~min}$, and then $10 \mu \mathrm{L}$ of the catalyst dispersion was loaded dropwise to the glassy carbon electrode under naturally dried. Then the freshly prepared working electrode was immersed in the electrolyte. The $\mathrm{IrO}_{2}$ acts as the control sample and the loading mass is about $0.71 \mathrm{mg} \mathrm{cm}^{-2}$. Notably, the SCE was calibrated before and after the tests. The potential was calibrated to the reversible hydrogen electrode (RHE) using the 
equation: $\mathrm{E}_{\mathrm{RHE}}=\mathrm{E}_{\mathrm{SCE}}+0.059 \mathrm{pH}+0.241-\mathrm{IR}$. $\mathrm{E}_{\mathrm{SCE}}$ is the experimental potential measured against the SCE reference electrode, and 0.241 is the standard potential of SCE at $25^{\circ} \mathrm{C}$. The polarization curves were IR corrected by $85 \%$ of the uncompensated solution resistance of ca. $8 \Omega$. The equation of $\eta(V)=\mathrm{E}_{(\mathrm{RHE})}-\mathrm{E}_{\theta}$ was used to calculate overpotential of these electrocatalysts, where $\mathrm{E}_{\theta}$ represents the thermodynamic potential for OER (1.23 V vs. RHE).

The working electrode was pre-treated in $1 \mathrm{M} \mathrm{KOH}$ with $\mathrm{N}_{2}$ flow before for electrochemical testing. The linear scanning voltammetry and Cyclic voltammetry (CV) were used to study the catalytic performance by sweeping the potential from 1 to $1.6 \mathrm{~V}$ vs. RHE at room temperature. The scanning rate was $5 \mathrm{mV} \mathrm{s}^{-1}$, unless otherwise noted. The electrochemical impedance spectroscopy (EIS) frequency range was $1000 \mathrm{KHz} \sim 0.01 \mathrm{~Hz}$ at the potential of $1.48 \mathrm{~V}$ vs. RHE.

The durability test was carried out by CV for 1000 cycles within the potential ranging from 1.03 to $1.63 \mathrm{~V}$ vs. RHE in $1 \mathrm{M} \mathrm{KOH}$ at $150 \mathrm{mV} \mathrm{s}^{-1}$, and a linear sweep was measured under a sweep rate of $5 \mathrm{mV} \mathrm{s}^{-1}$ after 1000 cycles. Chronoamperometry (CA) was carried out to estimate the stability of the catalyst at the potential of $1.48 \mathrm{~V}$ vs. RHE for 10 hours.

The electrochemical surface area (ECSA) was evaluated based on the doubler layer capacitance $\left(\mathrm{C}_{d l}\right)$. The ECSA was estimated by cyclic voltammetry $(\mathrm{CV})$ without Faradaic processes occurred region of $0.83 \mathrm{~V}-1.03 \mathrm{~V}$ where no Faradaic process occurred in $1 \mathrm{M}$ $\mathrm{KOH}$ at scan rate 20, 40, 60, 80 and $100 \mathrm{mV} \mathrm{s}^{-1}$.

The Turnover frequency (TOF) values were calculated from equation:

$$
\mathrm{TOF}=\frac{j * A}{4 * F * m}
$$


Where $\mathrm{j}$ is the current density at a specific potential, $\mathrm{A}$ is the surface area of the electrode, $\mathrm{F}$ is the Faraday constant $\left(96485 \mathrm{C} \mathrm{mol}^{-1}\right)$ and $\mathrm{m}$ is the number of moles of active materials.

The Faradaic efficiency of CoFe-F-16 was measured at $1.48 \mathrm{~V}$ for $1 \mathrm{~h}$ and calculated by the following equation.

$$
\text { Faradaic yield }=\frac{\mathrm{V}_{\text {Exp }}}{\mathrm{V}_{\text {Theor }}}=\frac{\mathrm{V}_{\text {Exp }}}{\frac{1}{4} \times \frac{Q}{F} \times V_{m}}
$$

Where the $V_{\text {Exp }}$ and $V_{\text {Theor }}$ are the experimental and theoretic volumes of the generated $\mathrm{O}_{2}$ gas during the catalytic process, $\mathrm{Q}$ is the charge passed through the electrode, $\mathrm{F}$ is Faraday constant $\left(96485 \mathrm{C} \mathrm{mol}^{-1}\right)$, the number 4 means 4 mole electrons per mole $\mathrm{O}_{2}, \mathrm{~V}_{\mathrm{m}}$ is the molar volume of gas $\left(24.5 \mathrm{~L} \mathrm{~mol}^{-1}, 298 \mathrm{~K}, 101 \mathrm{KPa}\right)$.

\section{Computational Methodology}

The atomic simulation software Atomic Simulation Environment (ASE) software package, GPAW calculator and Perdew-Burke-Ernzerhof (PBE) function are used to calculate the relevant exchange energy. The unit cell parameters of $\mathrm{CoF}_{2}$ are obtained from the Inorganic Crystal Structure Database (ISCD) in the software Findit. The space group parameter is $\mathrm{P} 42$, and the $\mathrm{CoF}_{2}$ model is created through unit cell optimization. The model was established in a $15 \AA$ vacuum environment without interference. The K-point is established in the Brillouin zone by using a $2 * 2 * 2$ monkhorst-pack grid, and the cut-off energy of the plane wave is set to $400 \mathrm{eV}$. When the maximum atomic force is lower than $0.05 \mathrm{eV} / \mathrm{A}$, the calculation ends. On the basis of the $\mathrm{CoF}_{2}$ model, one of the Co atoms was replaced with $\mathrm{Fe}$ atoms to construct a Fe-doped $\mathrm{CoFeF}_{2}$ model. 


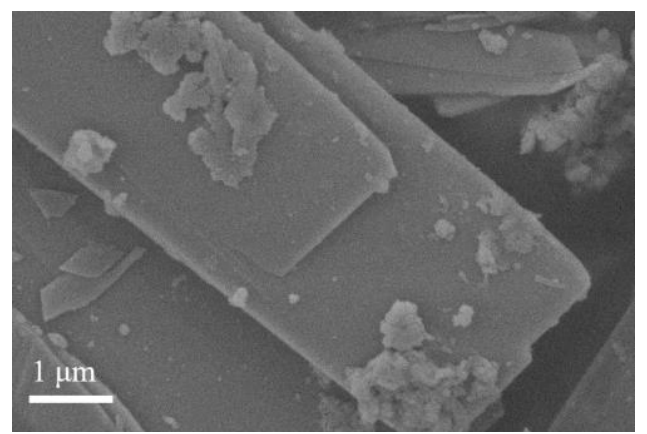

Figure S1. SEM images of CoFe-precursor.

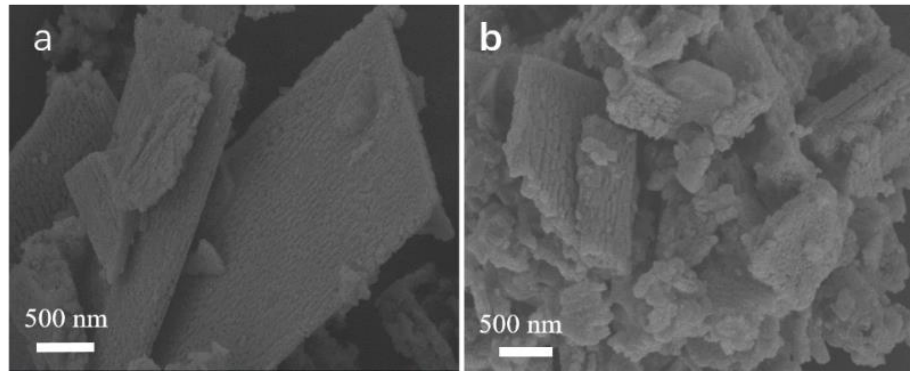

Figure S2. SEM images of CoFe-F-8 (a) and CoFe-F-32 (b).

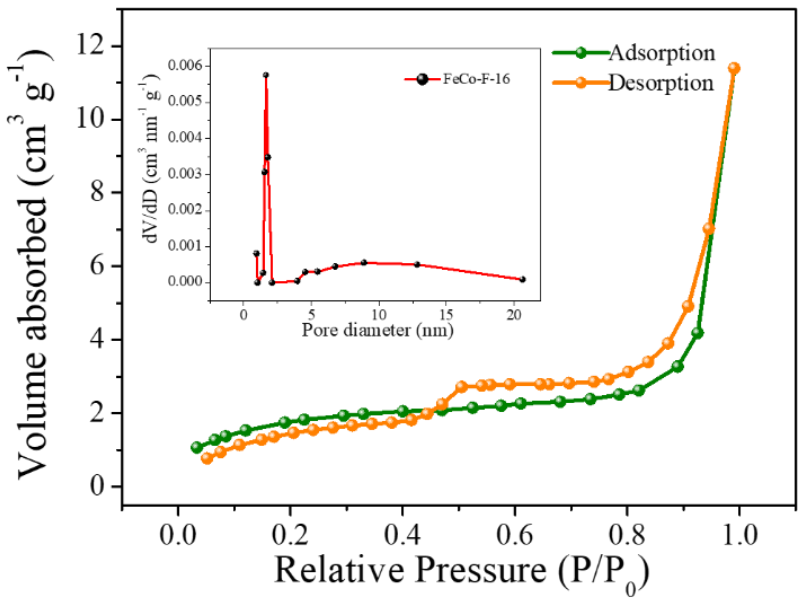

Figure S3. The nitrogen adsorption/desorption isotherms of CoFe-16. 

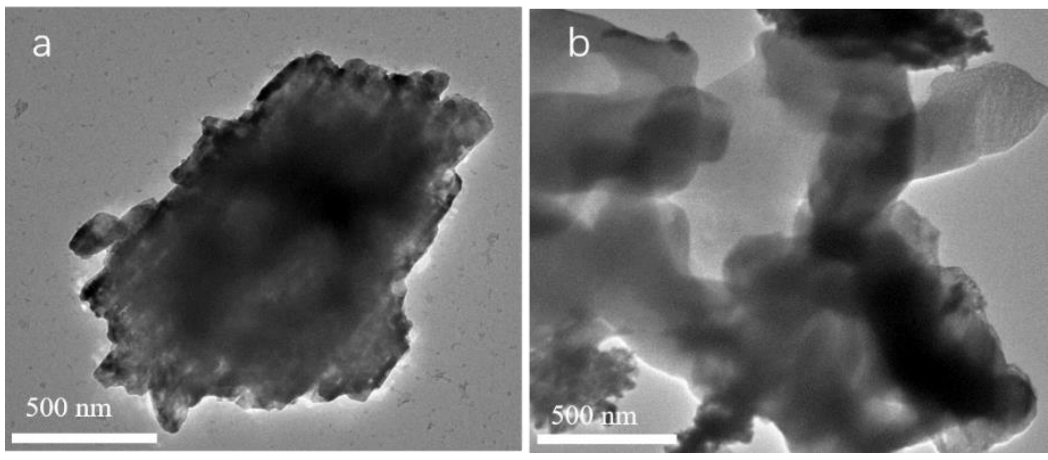

Figure S4. TEM images of (a) CoFe-F-8 and (b) CoFe-F-32.

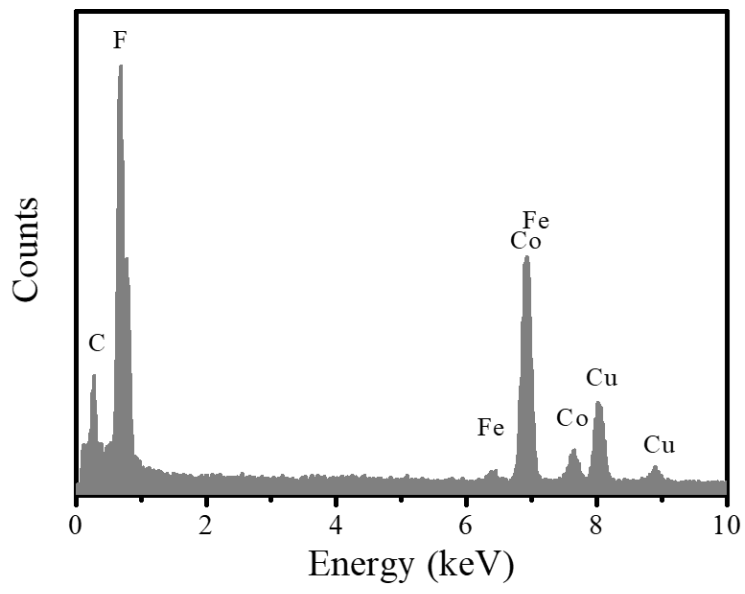

Figure S5. The EDX of CoFe-F-16.

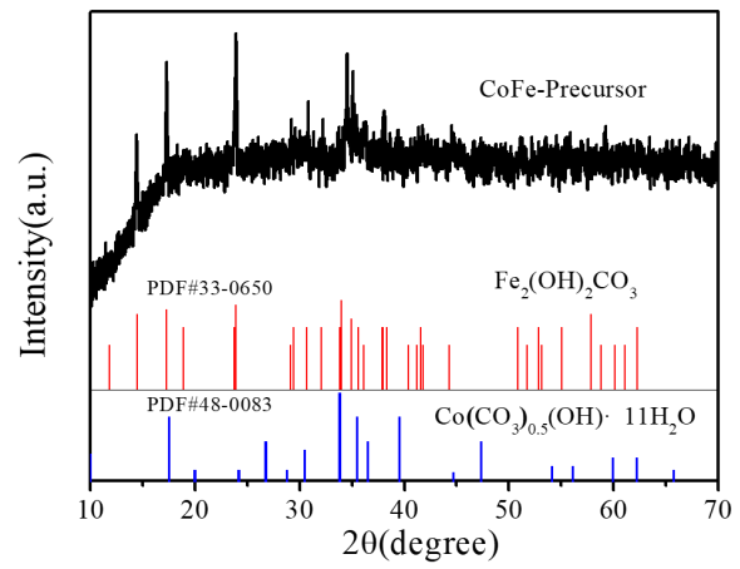

Figure S6. XRD pattern of the CoFe-precursor. 


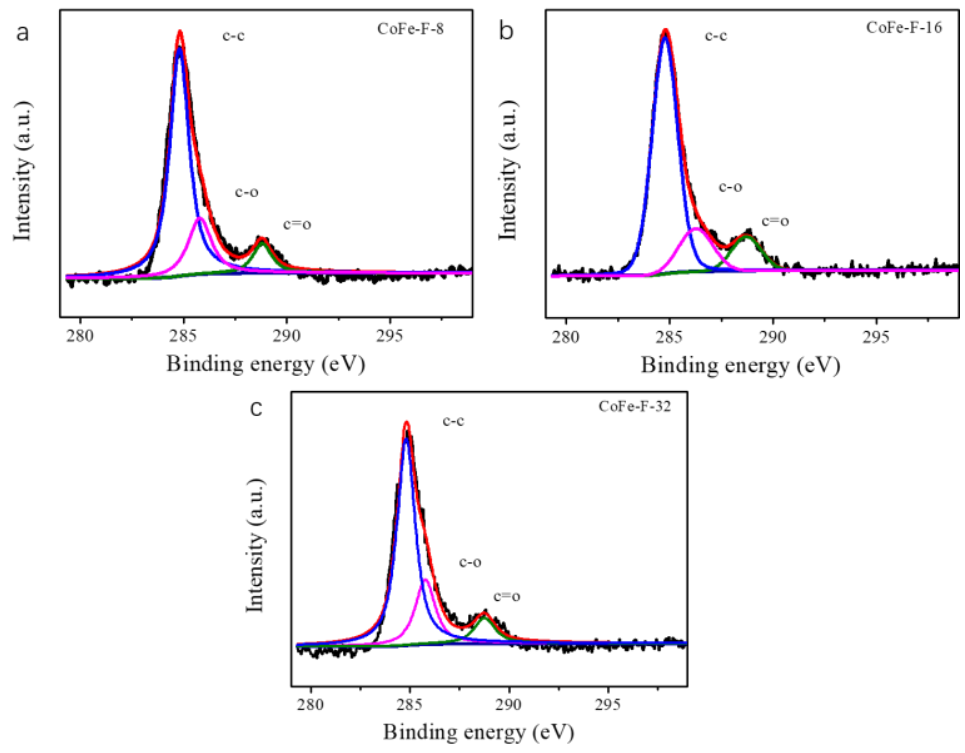

Figure S7. XPS spectrum of C 1s for (a) CoFe-F-8, (b) CoFe-F-16, and (c) CoFe-F-32.
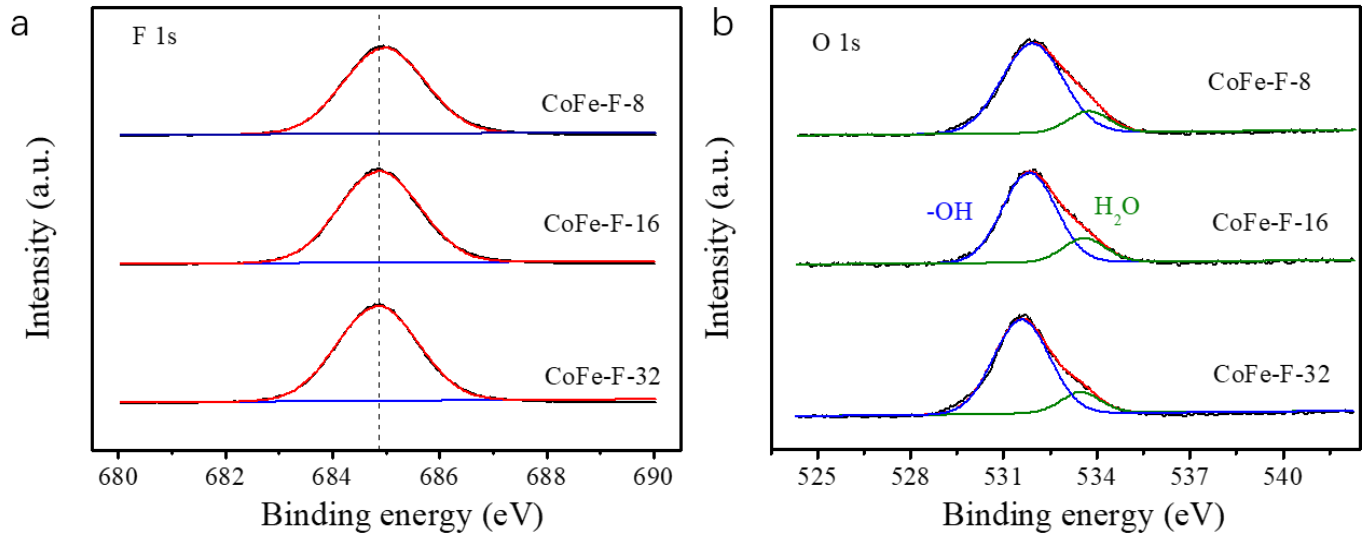

Figure S8. XPS spectrum of (a) F 1s, (b) O 1s for CoFe-F samples. 


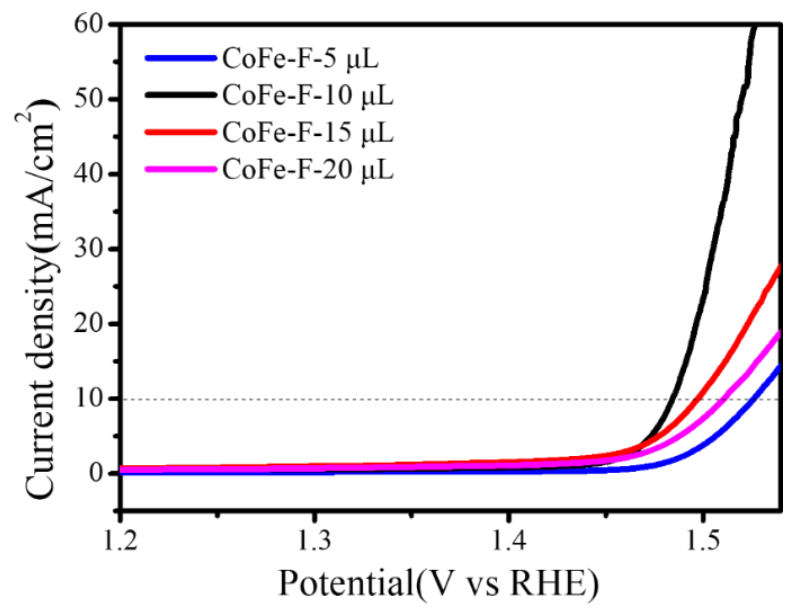

Figure S9. The OER performance of CoFe-F-16 with different loading mass.

The loading mass of CoFe-F-16 catalyst is controlled by dropping 5, 10, 15, and 20 $\mu \mathrm{L}$ of the catalyst ink onto the glassy carbon electrode $\left(0.07 \mathrm{~cm}^{2}\right)$ with the loading mass of $0.35,0.71,1.07$ and $1.43 \mathrm{mg} \mathrm{cm}^{-2}$. The trend of OER performance is shown in Figure S9. The optimal loading mass of the catalyst on a glassy carbon electrode $\left(0.07 \mathrm{~cm}^{2}\right)$ is 0.71 $\mathrm{mg} \mathrm{cm}{ }^{-2}$, which shows the best OER performance. CoFe-F-16 with a small loading mass of $0.35 \mathrm{mg} \mathrm{cm} \mathrm{m}^{-2}$ shows large overpotential due to the underutilization of the electrode surface. CoFe-F-16 with the small loading mass of 1.07 and $1.43 \mathrm{mg} \mathrm{cm}^{-2}$ shows large overpotential due to the decreased conductivity and reduced surface activity sites of electrode materials. 


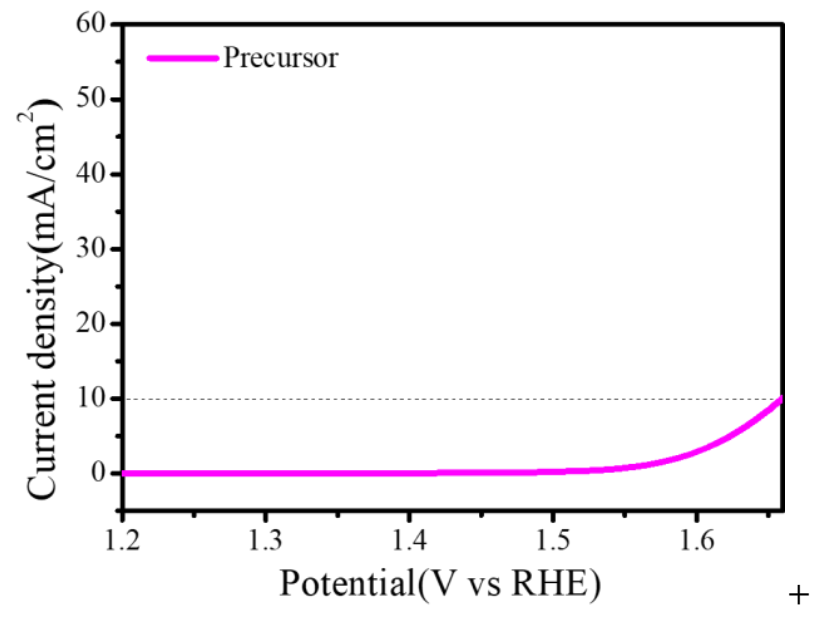

Figure S10. The polarization curve of Precursor in $1 \mathrm{M} \mathrm{KOH}$ at a scan rate of $5 \mathrm{mV} \mathrm{s}^{-1}$.

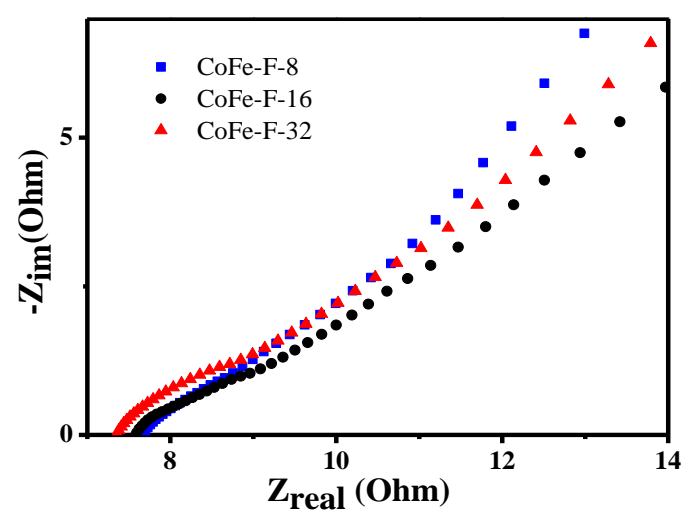

Figure S11. Nyquist plots of CoFe-F samples in high-frequency region at an overpotential of $252 \mathrm{mV}$. 

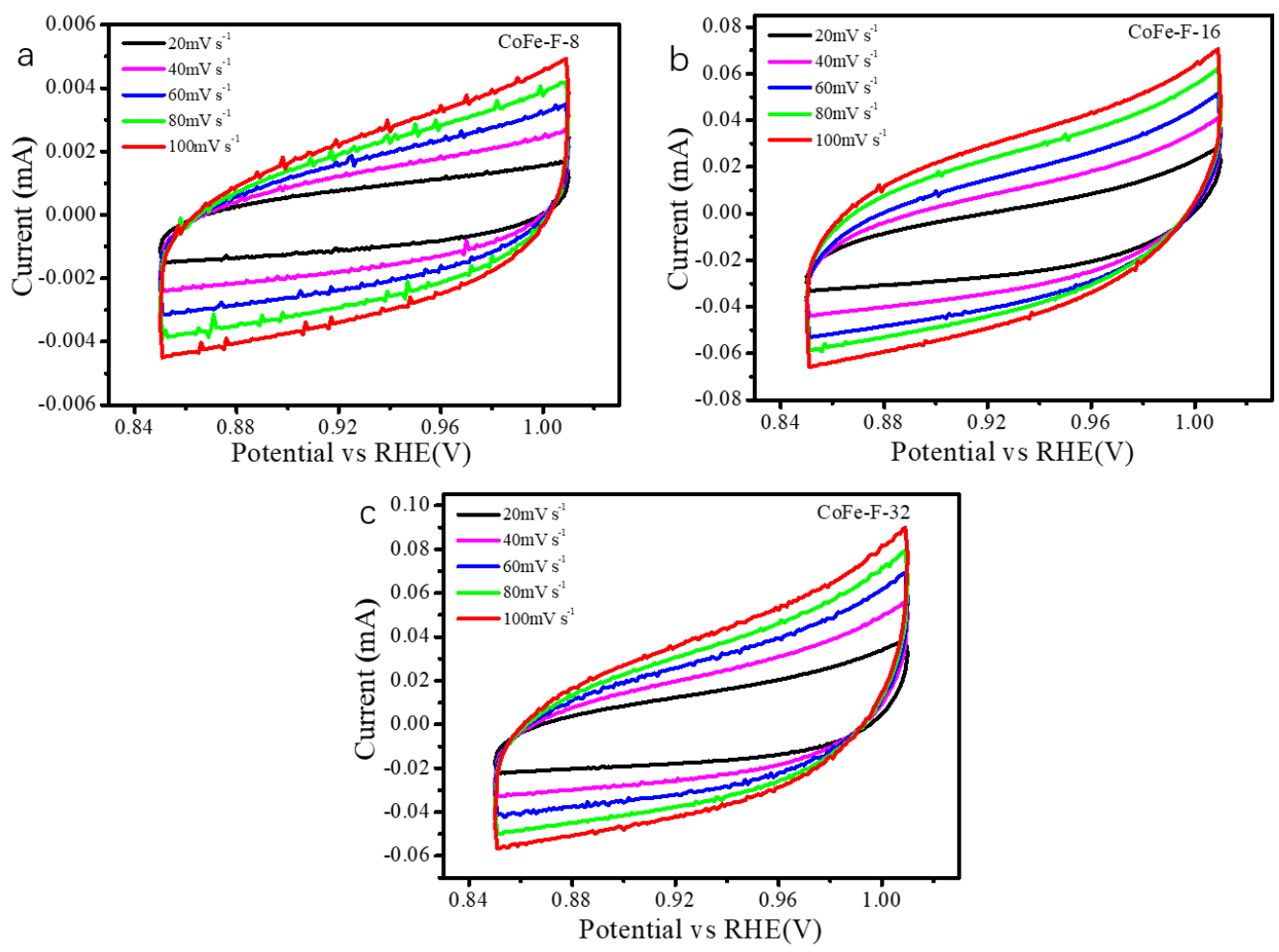

Figure S12. (a-c) Scan-rate dependent CVs of CoFe-F samples, respectively, at the potential of $0.83 \mathrm{~V}-1.03 \mathrm{~V}$ in $1 \mathrm{M} \mathrm{KOH}$.
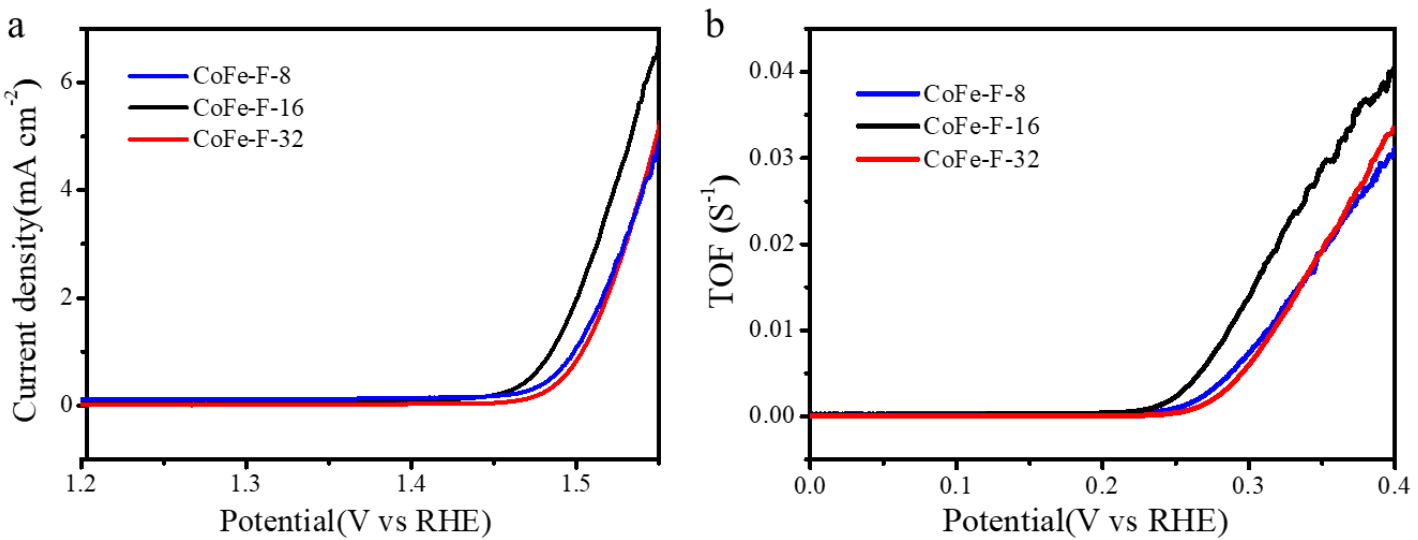

Figure S13. (a) Polarization of specific activity and (b) TOF value of CoFe-F samples. 


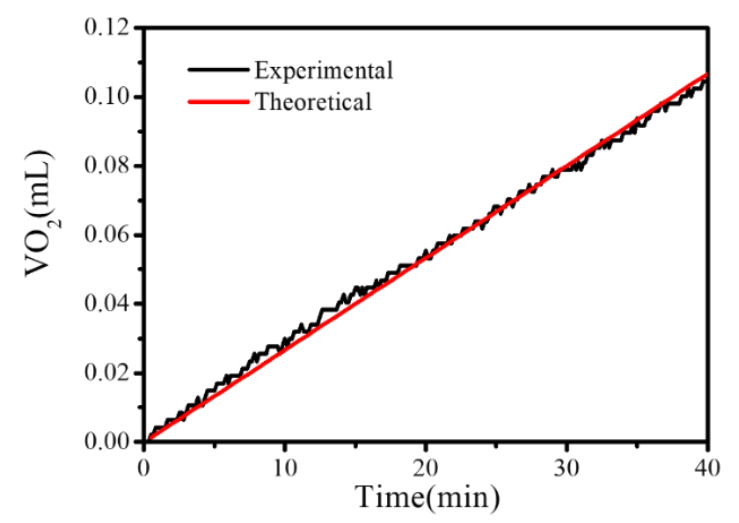

Figure S14. The experimental and theoretical amount of $\mathrm{O}_{2}$ generation during the catalytic process.

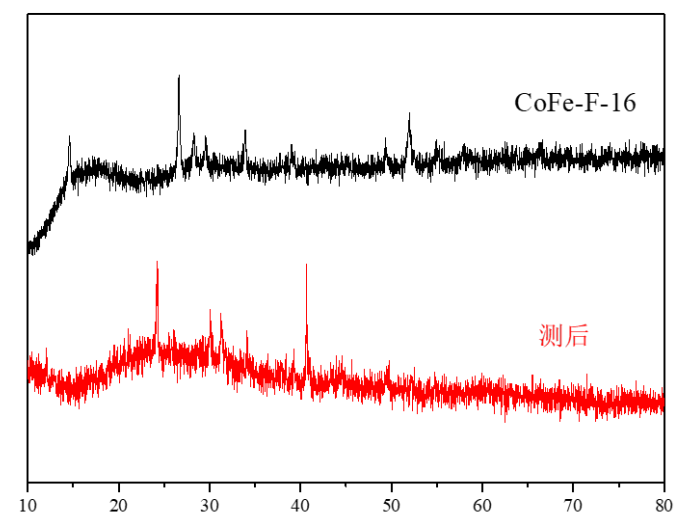

Figure S15. XRD pattern of the CoFe-F-16 catalyst before and after continuous CA test in $1.0 \mathrm{M} \mathrm{KOH}$
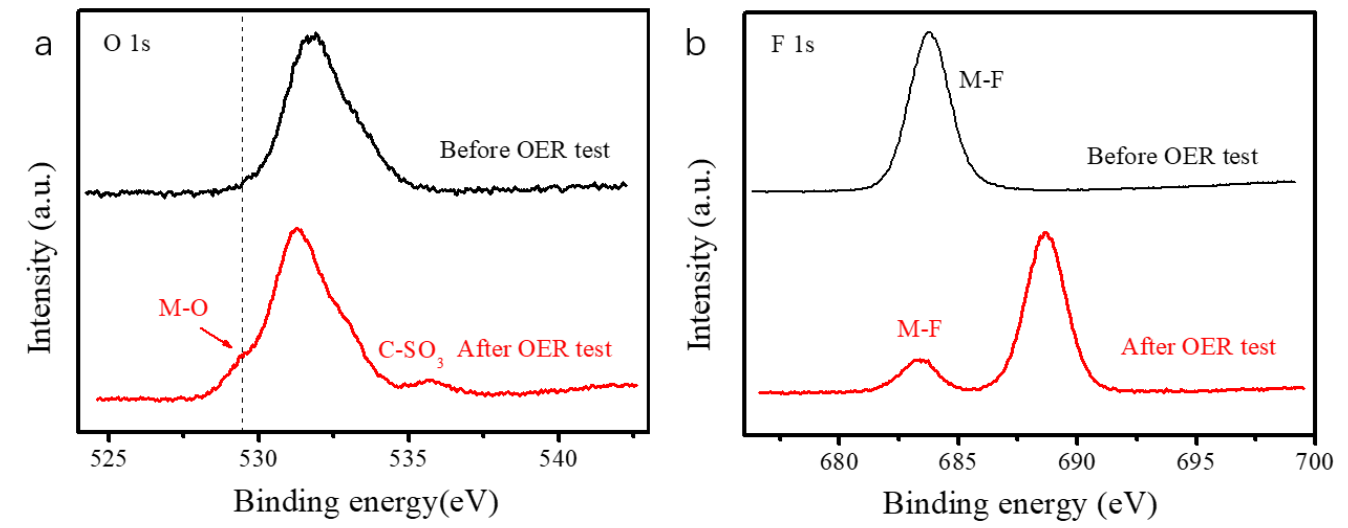

Figure S16. XPS spectra of (a) O 1s, (b) F 1s for CoFe-F-16 before and after the OER test. 


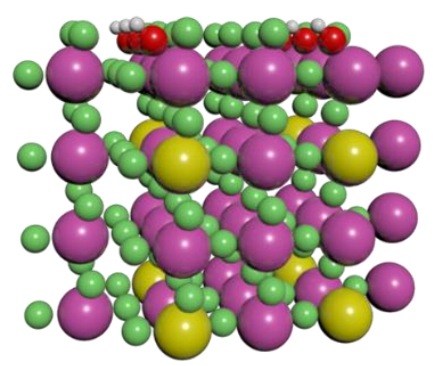

C $\mathrm{F} \cap \mathrm{Co}$
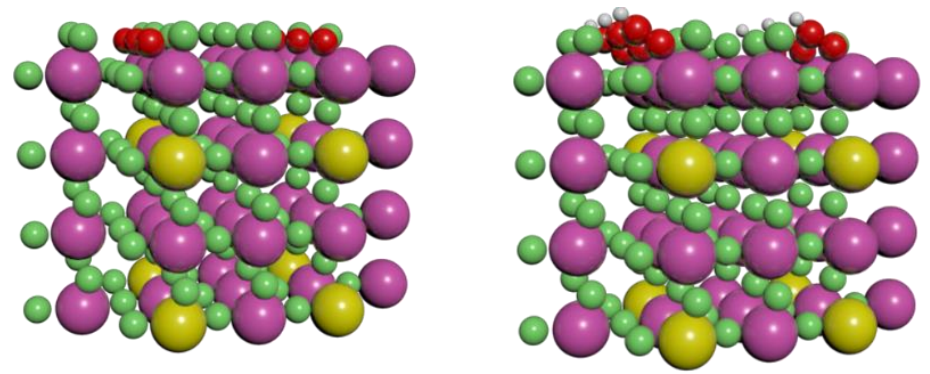

C $\mathrm{O}$
C. $* \mathrm{OH}$

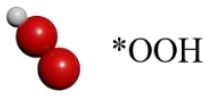

Figure S17. The adsorption of (a) $* \mathrm{OH},(\mathrm{b}) * \mathrm{O}$ and (c) $* \mathrm{OOH}$ at the simulated active sites of CoFe-F-16.

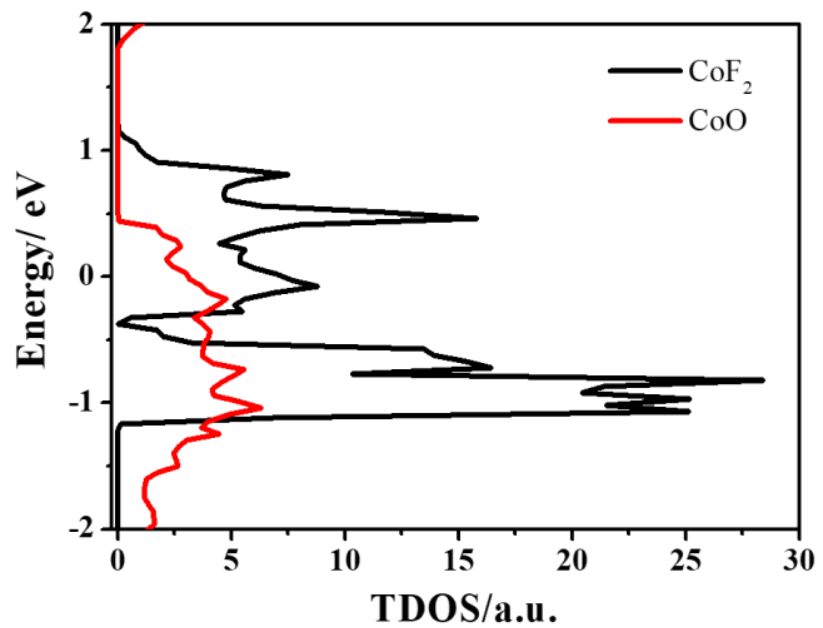

Figure S18. The density of states of $\mathrm{CoO}$ and $\mathrm{CoF}_{2}$. 
Table S1. The value of $\mathrm{C}_{d l}$, ECSA and Rf for CoFe-F samples.

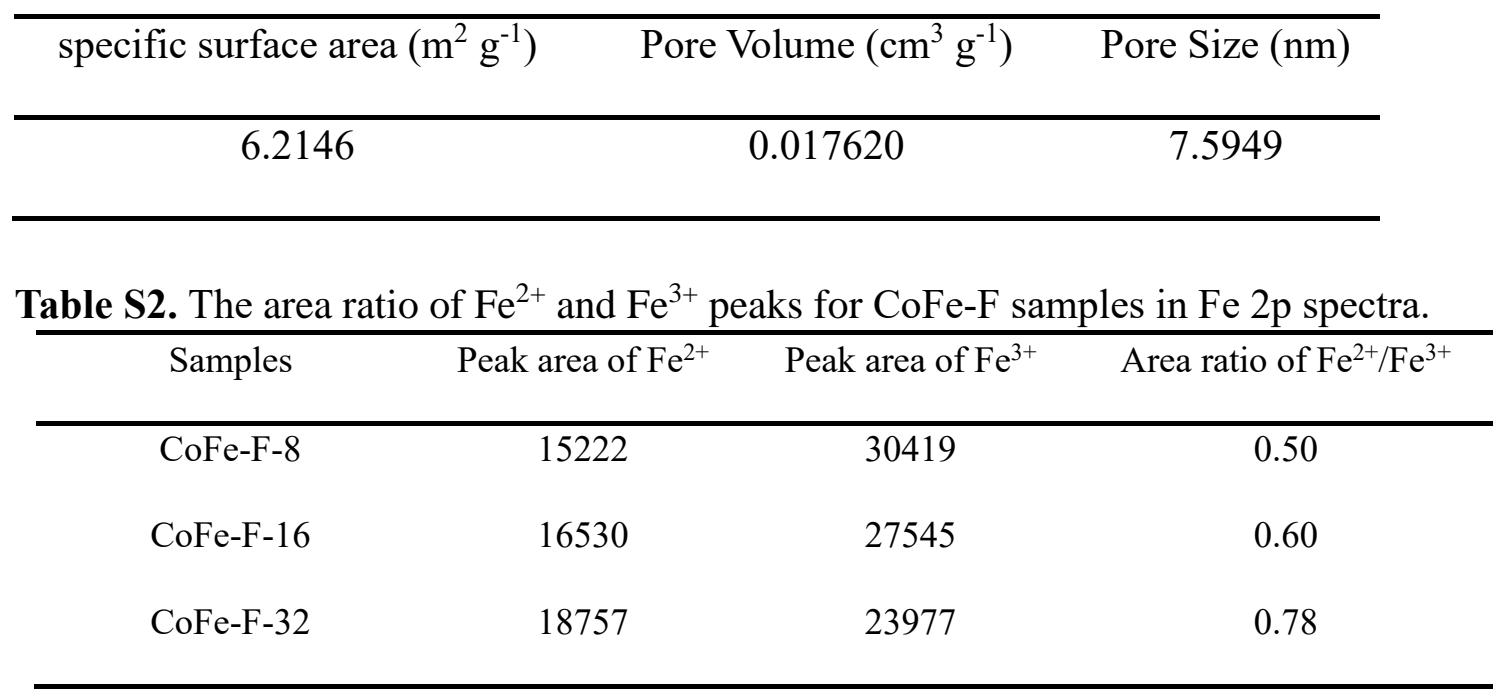

Table S3. The comparison of other OER catalysts derived from transition metal based materials in $1 \mathrm{M} \mathrm{KOH}$.

\begin{tabular}{|c|c|c|c|}
\hline Materials & Morphology & $\begin{array}{l}\text { Overpotential } \\
\qquad(\mathrm{mV})\end{array}$ & Ref \\
\hline CoFe-F-16 & Nanosheet & 252 & This work \\
\hline CoFeP-NFs/NPCNT & Hollow nanoframe & 278 & 1 \\
\hline NG-NiFe@ $\mathrm{MoC}_{2}-2$ & Nanoparticle & 300 & 2 \\
\hline $\mathrm{CoSe}_{2}$ & Nanobox & 335 & 3 \\
\hline $\mathrm{NPC} / \mathrm{Co}_{2} \mathrm{NiOx}$ & Nanosphere & 330 & 4 \\
\hline $\mathrm{Co}_{0.4} \mathrm{Fe}_{0.28} \mathrm{~S}$ & Nanocube & 270 & 5 \\
\hline NCF-MOF & Nanocuboid & 320 & 6 \\
\hline $\mathrm{CoFe}_{2} \mathrm{O}_{4}$ & Thin film & 266 & 7 \\
\hline $\mathrm{Co}_{3} \mathrm{O}_{4} / \mathrm{Co}-\mathrm{Fe}$ & Nanobox & 297 & 8 \\
\hline $\mathrm{FeNi} / \mathrm{NiFe}_{2} \mathrm{O}_{4} @ \mathrm{NC}$ & Sphere & 316 & 9 \\
\hline NiFe@NC & Core shell & 258 & 10 \\
\hline $\mathrm{NiCoP} / \mathrm{C}$ & Nanobox & 330 & 11 \\
\hline NiCoP/NC PHCs & Nanocage & 297 & 12 \\
\hline $\mathrm{Sr}_{2} \mathrm{Fe}_{1.3} \mathrm{Ni}_{0.2} \mathrm{Mo}_{0.5} \mathrm{O}_{6-\delta}$ & Microsphere & 360 & 13 \\
\hline CoFe@NC-NCNT-H & Nanoparticle & 380 & 14 \\
\hline $\mathrm{N}-\mathrm{Co}_{3} \mathrm{O}_{4} @ \mathrm{NC}$ & Nanocube & 266 & 15 \\
\hline $\mathrm{NCNT} / \mathrm{NieNiFe}_{2} \mathrm{O}_{4}$ & Nanotube & 340 & 16 \\
\hline Ni-Co-F-1,1 & Nanosheet & 300 & 17 \\
\hline $\mathrm{FePO}_{4} / \mathrm{NF}$ & Nanosheet & 310 & 18 \\
\hline CoPO NS & Nanosheet & 320 & 19 \\
\hline $\mathrm{A}_{2.7} \mathrm{~B}-\mathrm{MOF}-\mathrm{FeCo}{ }_{1.6}$ & Rod-like & 288 & 20 \\
\hline
\end{tabular}


Table S4. EIS fitting parameters from equivalent circuits for CoFe-F nanosheets with different proportions of fluorination in $1 \mathrm{M} \mathrm{KOH}$.

\begin{tabular}{cccc}
\hline Catalysts & $\mathrm{R}_{\mathrm{s}} / \Omega$ & $\mathrm{R}_{\mathrm{ct}} / \Omega$ & $\mathrm{R}_{1} / \Omega$ \\
\hline CoFe-F-8 & 7.68 & 62.9 & 58.72 \\
CoFe-F-16 & 7.09 & 37.98 & 11.92 \\
CoFe-F-32 & 7.22 & 203.7 & 155.4 \\
\hline
\end{tabular}

$\mathrm{R}_{\mathrm{s}}$ represents the uncompensated solution resistance, and $\mathrm{R}_{1}$ is for the interface resistance of the catalysts coated on the glass carbon electrode.

Table S5. The value of $C_{d l}, E C S A$ and $R_{f}$ for CoFe-F samples.

\begin{tabular}{cccc}
\hline Samples & $C_{d l}\left(\mathrm{mF} \mathrm{cm}^{-1}\right)$ & $E C S A\left(\mathrm{~cm}^{-2}\right)$ & $R_{f}$ \\
\hline CoFe-F-8 & 0.25 & 0.44 & 6.29 \\
CoFe-F-16 & 0.32 & 0.56 & 8 \\
CoFe-F-32 & 0.29 & 0.51 & 7.29 \\
\hline
\end{tabular}




\section{References}

1. Li, W.; Chen, Y.; Yu, B.; Hu, Y.; Wang, X.; Yang, D., 3D hollow Co-Fe-P nanoframes immobilized on N,P-doped CNT as an efficient electrocatalyst for overall water splitting. Nanoscale 2019, 11, 17031-17040.

2. Hu, Q.; Liu, X.; Zhu, B.; Fan, L.; Chai, X.; Zhang, Q.; Liu, J.; He, C.; Lin, Z., Crafting $\mathrm{MoC}_{2}$-doped bimetallic alloy nanoparticles encapsulated within $\mathrm{N}$-doped graphene as roust bifunctional electrocatalysts for overall water splitting. Nano Energy 2018, 50, 212-219.

3. Ganesan, V.; Kim, J., Prussian blue analogue metal organic framework-derived $\mathrm{CoSe}_{2}$ nanoboxes for highly efficient oxygen evolution reaction. Mater. Lett. 2018, 223, 49-52.

4. Wang, J.; Zeng, H. C., Hybrid OER electrocatalyst combining mesoporous hollow spheres of N, P-Doped carbon with ultrafine $\mathrm{Co}_{2} \mathrm{NiO}_{x}$. ACS Appl. Mater. Inter. 2020,12, 50324-50332.

5. Cao, Z.; Zhou, T.; Xi, W.; Zhao, Y., Bimetal metal-organic frameworks derived $\mathrm{Co}_{0.4} \mathrm{Fe}_{0.28} \mathrm{P}$ and $\mathrm{Co}_{0.37} \mathrm{Fe}_{0.26} \mathrm{~S}$ nanocubes for enhanced oxygen evolution reaction. Electrochim. Acta 2018, 263, 576-584.

6. Ahn, W.; Park, M. G.; Lee, D. U.; Seo, M. H.; Jiang, G.; Cano, Z. P.; Hassan, F. M.; Chen, Z., Hollow Multivoid Nanocuboids Derived from Ternary Ni-Co-Fe Prussian Blue Analog for Dual-Electrocatalysis of Oxygen and Hydrogen Evolution Reactions. Adv. Funct. Mater. 2018, 28, 1802129.

7. Lei, S.; Li, Q.-H.; Kang, Y.; Gu, Z.-G.; Zhang, J., Epitaxial growth of oriented prussian blue analogue derived well-aligned $\mathrm{CoFe}_{2} \mathrm{O}_{4}$ thin film for efficient oxygen evolution reaction. Appl. Catal. B-Environ. 2019, 245, 1-9. 
8. Wang, X.; Yu, L.; Guan, B. Y.; Song, S.; Lou, X. W., Metal-Organic Framework Hybrid-Assisted Formation of $\mathrm{Co}_{3} \mathrm{O}_{4} / \mathrm{Co}-\mathrm{Fe}$ Oxide Double-Shelled Nanoboxes for Enhanced Oxygen Evolution. Adv. Mater. 2018, 30, 1801211.

9. Yang, Y.; Lin, Z.; Gao, S.; Su, J.; Lun, Z.; Xia, G.; Chen, J.; Zhang, R.; Chen, Q., Tuning Electronic Structures of Nonprecious Ternary Alloys Encapsulated in Graphene Layers for Optimizing Overall Water Splitting Activity. Acs Catal. 2017, 7, 469479.

10. Du, L.; Luo, L.; Feng, Z.; Engelhard, M.; Xie, X.; Han, B.; Sun, J.; Zhang, J.; Yin, G.; Wang, C.; Wang, Y.; Shao, Y., Nitrogen-doped graphitized carbon shell encapsulated NiFe nanoparticles: A highly durable oxygen evolution catalyst. Nano Energy 2017, 39, 245-252.

11. He, P.; Yu, X.-Y.; Lou, X. W., Carbon-Incorporated Nickel-Cobalt Mixed Metal Phosphide Nanoboxes with Enhanced Electrocatalytic Activity for Oxygen Evolution. Angew. Chem.-Int. Edit. 2017, 56, 3897-3900.

12. Zhang, X.; Huang, L.; Wang, Q.; Dong, S., Transformation of homobimetallic MOFs into nickel-cobalt phosphide/nitrogen-doped carbon polyhedral nanocages for efficient oxygen evolution electrocatalysis. J. Mater. Chem. A 2017, 5, 18839-18844.

13. Zhang, J.; Duan, Y.; Zhu, Y.; Wang, Y.; Yao, H.; Mi, G., Evenly dispersed microspherical amorphous alloy CoxB1-x: Robust and magnetically recyclable catalyst for alcoholyzing ammonia borane to release H-2. Mater. Chem. Phys. 2017, 201, 297-301.

14. Shang, Z.; Chen, Z.; Zhang, Z.; Yu, J.; Tan, S.; Ciucci, F.; Shao, Z.; Lei, H.; Chen, D., CoFe nanoalloy particles encapsulated in nitrogen-doped carbon layers as bifunctional oxygen catalyst derived from a Prussian blue analogue. J. Alloy. Compd. 2018, 
$740,743-753$.

15. Wang, Z.; Xu, W.; Chen, X.; Peng, Y.; Song, Y.; Lv, C.; Liu, H.; Sun, J.; Yuan, D.; Li, X.; Guo, X.; Yang, D.; Zhang, L., Defect-Rich Nitrogen Doped $\mathrm{Co}_{3} \mathrm{O}_{4} / \mathrm{C}$ Porous Nanocubes Enable High-Efficiency Bifunctional Oxygen Electrocatalysis. Adv. Funct. Mater. 2019, 29, 1902875.

16. Qin, Y.; Wang, F.; Shang, J.; Iqbal, M.; Han, A.; Sun, X.; Xu, H.; Liu, J., Ternary NiCoFe-layered double hydroxide hollow polyhedrons as highly efficient electrocatalysts for oxygen evolution reaction. J. Energy Chem. 2020, 43, 104-107.

17. Xue, Y.; Wang, Y.; Liu, H.; Yu, X.; Xue, H.; Feng, L., Electrochemical oxygen evolution reaction catalyzed by a novel nickel-cobalt-fluoride catalyst. Chem. Commun. 2018, 54, 6204-6207.

18. Yang, L.; Guo, Z.; Huang, J.; Xi, Y.; Gao, R.; Su, G.; Wang, W.; Cao, L.; Dong, B., Vertical Growth of 2D Amorphous $\mathrm{FePO}_{4}$ Nanosheet on Ni Foam: Outer and Inner Structural Design for Superior Water Splitting. Adv. Mater. 2017, 29, 1704574.

19. Xiang, R.; Duan, Y.; Tong, C.; Peng, L.; Wang, J.; Shah, S. S. A.; Najam, T.; Huang, X.; Wei, Z., Self-standing FeCo Prussian blue analogue derived $\mathrm{FeCo} / \mathrm{C}$ and $\mathrm{FeCoP} / \mathrm{C}$ nanosheet arrays for cost-effective electrocatalytic water splitting. Electrochim. Acta 2019, 302, 45-55.

20. Xue, Z.; Li, Y.; Zhang, Y.; Geng, W.; Jia, B.; Tang, J.; Bao, S.; Wang, H.P.; Fan, Y.; Wei, Z.-w.; Zhang, Z.; Ke, Z.; Li, G.; Su, C.-Y., Supporting information of modulating electronic structure of Metal-Organic Framework for efficient electrocatalytic oxygen evolution. Adv. Energy Mater. 2020, 10, 1801564. 